\title{
Hysteresis analysis on petrophysical and mechanical properties of carbonate rocks
}

Davi Kezen Padrão Manhães, Guilherme Rodrigues Lima, Roseane Marchezi Misságia, Marco Antônio Rodrigues de Ceia. Laboratório de Engenharia e Exploração de Petróleo (LENEP) - Universidade Estadual do Norte Fluminense (UENF)

Copyright 2016, SBGf - Sociedade Brasileira de Geofísica

Este texto foi preparado para a apresentação no VII Simpósio Brasileiro de Geofísica, Ouro Preto, 25 a 27 de outubro de 2016. Seu conteúdo foi revisado pelo Comitê Técnico do VII SimBGf, mas não necessariamente representa a opinião da SBGf ou de seus associados. É proibida a reprodução total ou parcial deste material para propósitos comerciais sem prévia autorização da SBGf.

\section{Abstract}

Hydrostatic compression tests on rocks, if conducted at stresses below failure, typically exhibit both non-linearity and hysteresis in the stress-strain curve. This behavior can be associated with the presence of cracks and pores.

In this work, porosity and bulk volume deformation were analyzed and the different behavior under loading/ unloading conditions reveals the grain/pore interaction influence on these properties.

Experiments were conducted increasing hydrostatic pressure from $400 \mathrm{psi}$ to $1000 \mathrm{psi}$, registering loading and unloading data, on carbonate samples of American outcrops.

The dissipated energy related to frictional sliding and adhesion effect, during confinement cycle, was estimated by the area of hysteresis loop in the effective pressure versus bulk volume graph.

\section{Introduction}

Geomechanical understanding of reservoir is controlled by yielding, failure, and elastic processes, which are strongly related to mineralogical composition, porosity and pore structure. There is a lot of previous work dedicated to analyze these properties (David et al., 2012).

Most part of these works, meanwhile, does not make any references to the unloading data. It means: Does the rock loading behavior the same on unloading? Three main factors govern the differences between these two modes: The porous volume available to be deformed, the grain shapes alterations and the number of contacts grain/grain, grain/pore and pore/pore, which are determinant on the friction and adhesion coefficients calculation.

If the cracks of a porous rock are all open and randomly distributed, the overall response is isotropic. Otherwise, if some preferential cracks start to close, it causes frictional sliding and the overall response will depends on the loading conditions (Nejati et al., 2013).

Mukul (1994) reports adhesion as a mechanism associated with asperities, relating roughness with the confinement pressure required to cause attenuation in local contact surfaces.
According to Garcia et al. (2006), characterization of the hysteretic behavior of rock materials is essential for the propitious monitoring of depletion rates on reservoirs.

The magnitude of the hysteresis cycles is related to the attenuation properties of the rocks and to explain the phenomena, it is important to investigate the relationship between friction and adhesion (Tutuncu et al., 1998).

The objective of this work is to analyze the influence of the pore structure compression on petrophysical and mechanical properties, giving particular attention to the phenomena occurring on each loading/unloading stage.

\section{Methodology}

The experiments were carried out using four cylindrical samples at Petrophysics Laboratory of UENF/LENEP. Initially, each specimen was previously oven-dried at 100 ${ }^{0} \mathrm{C}$ for 8-24 $\mathrm{h}$ to reduce humidity and Ultrapore system was used to determine the grain volume.

The samples were submitted to porosity measurements on the Coreval 700 . The equipment is capable of acquiring data from rock samples while hydrostatic confinement pressures are applied performing a loadingunloading cycle from 400 psi up to 1000 psi. The maximal stress (1000 psi) chosen, which was the same for all four tests, is less than approximately $20 \%$ of the UCS (Table 1).

Measurements were taken from each rock sample three times on each confinement pressure stage, to guarantee data accuracy.

The equipment measures porosity, bulk volume and length and diameter of samples, through a piezoelectric transducer, on each confinement stage.

Effective pressure $\left(P_{\text {eff }}\right)$, relative porosity $\left(\phi_{\text {rel }}\right)$ and volumetric deformation $\left(\varepsilon_{\mathrm{vol}}\right)$ are defined as:

$$
\begin{aligned}
& P_{\text {eff }}=P_{c}-P_{p} \\
& \phi_{\text {rel }}=\left(\phi-\phi_{0}\right) / \phi_{0} \\
& \varepsilon_{\text {vol }}=\left(V_{b}-V_{b 0}\right) / V_{b 0}
\end{aligned}
$$

Where:

$$
\begin{aligned}
& P_{c}-\text { Confinement pressure } \\
& P_{p}-\text { Pore pressure } \\
& \phi-\text { Porosity } \\
& \phi_{0}-\text { Porosity at atmospheric pressure } \\
& V_{b}-\text { Bulk volume }
\end{aligned}
$$


Table 1 shows the main measured properties for the samples.

\begin{tabular}{lllllll}
\hline Sample code & Description & $\mathrm{V}_{\mathrm{g}}\left[\mathrm{cm}^{3}\right]$ & $\mathrm{L}_{0}[\mathrm{~mm}]$ & $\mathrm{D}_{0}[\mathrm{~mm}]$ & $\mathrm{V}_{\mathrm{b} 0}\left[\mathrm{~cm}^{3}\right]$ & UCS [psi] \\
\hline SD & Silurian Dolomite & 64.42 & 65.19 & 38.21 & 74.75 & 8000 \\
ILS-70 & Indiana Limestone & 61.38 & 65.26 & 38.26 & 75.03 & 5000 \\
ILS-10 & Indiana Limestone & 67.18 & 64.44 & 38.23 & 73.97 & 5000 \\
EW & Edward White & 49.76 & 65.05 & 37.67 & 72.50 & 5000 \\
\hline
\end{tabular}

Table 1 - Samples characteristics

Here:

$\mathrm{V}_{\mathrm{g}}$ - Grain volume

Lo - Length at atmospheric pressure

$D_{0}$ - Diameter at atmospheric pressure

$\mathrm{V}_{\mathrm{b} 0}$ - Bulk volume at atmospheric pressure

UCS - Ultimate compressive strength

\section{Results}

Figures following revealed two main behaviors observed on the four samples analyzed: EW and SD (Figures 1 and 2) exhibited well-defined hysteretic behaviors, while ILS10 and ILS-70 (Figures 3 and 4) showed a non-welldefined hysteretic behavior, remaining, meanwhile, in the elastic mechanic regime, considering that the residual deformations are not substantial.

Red points represents loading, while black points unloading conditions for all plots.
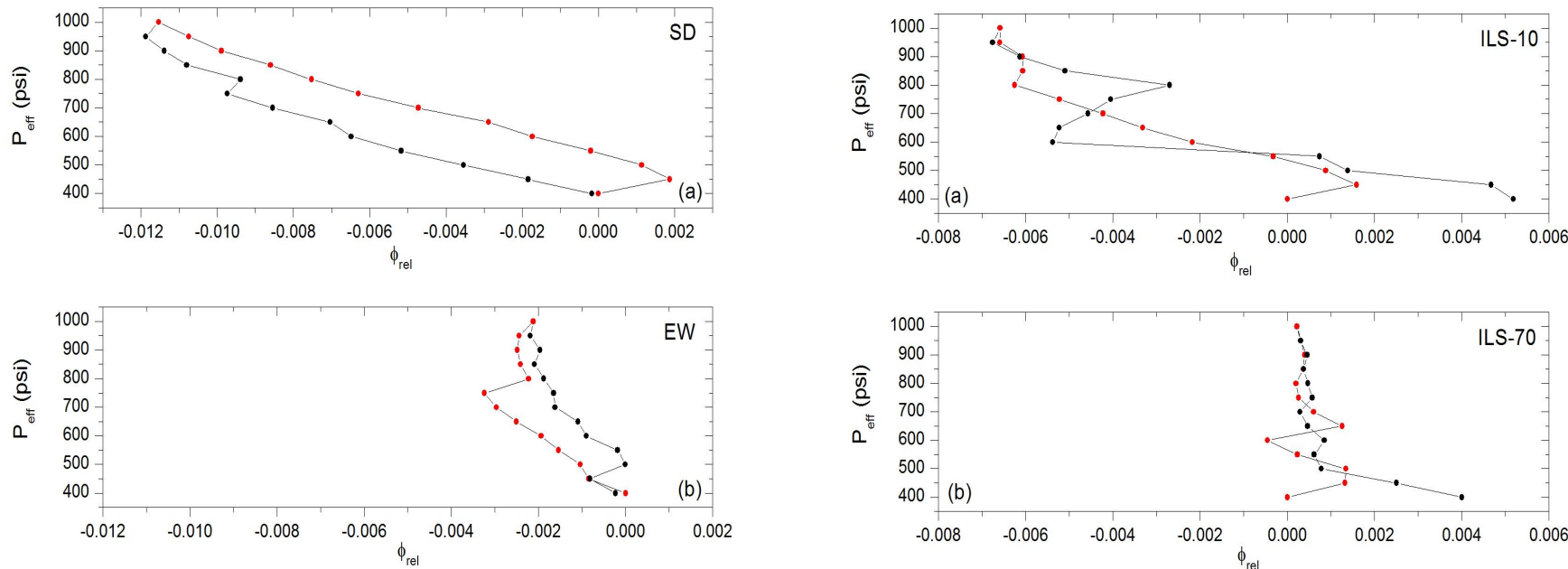

Figure 1 - Relative porosity varying with confinement pressure for $S D$ (a) and EW (b)
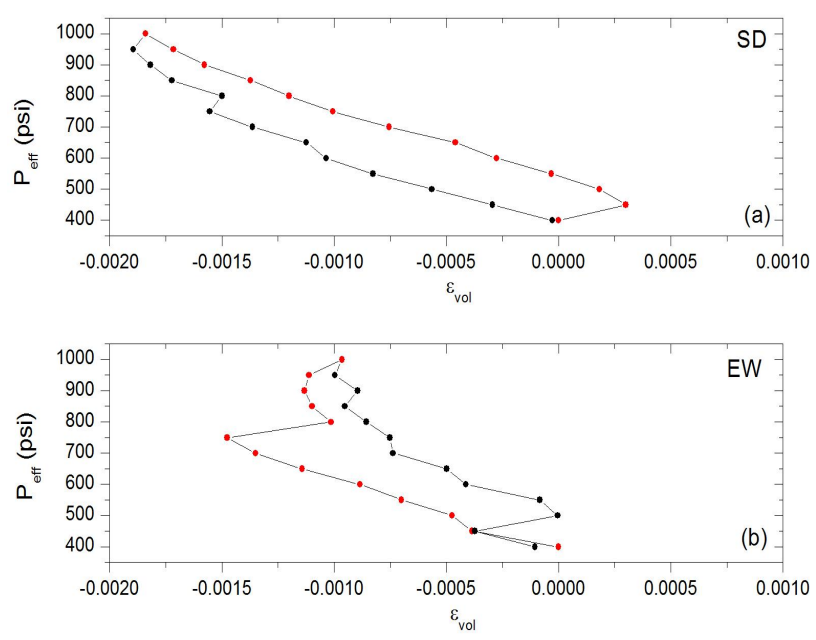

Figure 2 - Volumetric deformation varying with confinement pressure for SD (a) and EW (b)

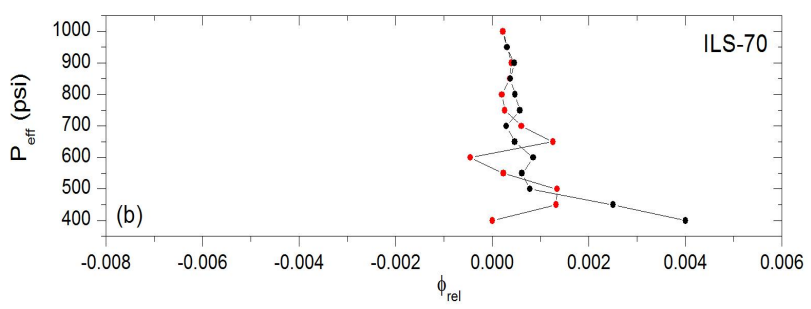

Figure 3 - Relative porosity varying with confinement pressure for ILS-10 (a) and ILS-70 (b). 

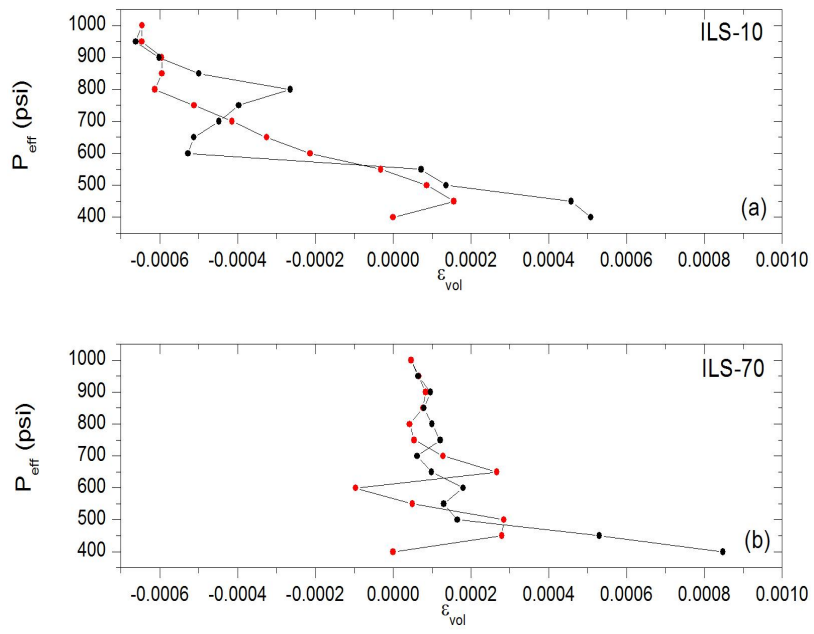

Figure 4 - Volumetric deformation varying with confinement pressure for ILS-10 (a) and ILS-70 (b)

Figure 5 shows the relationship between the confinement pressure and the bulk volume of SD and EW samples. The area between the loading/unloading curves was calculated to estimate the magnitude of the hysteresis, which allows correlating the internal frictional and adhesion processes occurring inside the sample during the tests with its attenuation properties.

EW exhibits a dissipation energy of $0.10377 \mathrm{~J}$ (area between its two curves on figure 5) and SD of $0.14927 \mathrm{~J}$.

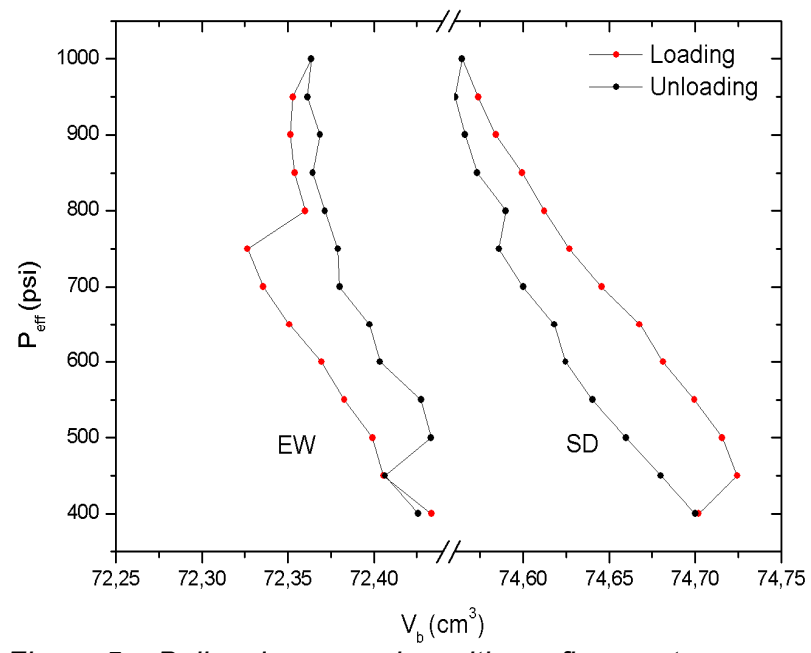

Figure 5 - Bulk volume varying with confinement pressure

\section{Discussion and conclusions}

As higher is the area between loading/unloading curves, more dissipative are the samples, it means, the difference between the energy required to cause sample's deformation and the energy required to return it to its original mode is higher and, consequently, the attenuation on the sample will be more relevant, because during the passage of a compressional or shear acoustic wave on the sample, more energy will be lost causing its elastic deformation.

For EW, which is a sample of higher porosity (around $30 \%$ ), deformations were easier to be made on loading conditions. In contrast, on SD, which is a sample with porosity around $13 \%$, deformations were easier caused on unloading conditions.

It allows concluding that in samples with higher porosity, which has a larger number of possible contact between grain's surfaces, the adhesion mechanisms is more weighty that in samples with lower porosities, which for friction between the grain's surfaces act more intense as a deformation mechanism.

The area between the two curves has a unique meaning: Despite the two possible mechanisms acting, both causes the dissipation of the energy on the rock, in other words, as much more adhesion or frictional processes occurring in the sample, as much more attenuation it causes.

EW shows a dissipation energy of $0.10377 \mathrm{~J}$ (area between its two curves on Figure 5) and SD shows it equals to $0.14927 \mathrm{~J}$, so, due respect to the frictional sliding and adhesion processes occurring during elastic deformations, SD causes more seismic waves attenuation than EW.

\section{Agradecimentos}

Authors thank UENF/LENEP, PRH-226-PETROBRAS and CAPES for facilities, financial support and scholarship.

\section{Referências}

David, E.C., Brantut, N., Schubnel, A., Zimmerman, R.W., 2012. Sliding crack model for nonlinearity and hysteresis in the uniaxial stress-strain curve of rock. International Journal of Rock Mechanics \& Mining Sciences, 52: 9-17.

García, X., Medina, E.A., 2006. Hysteresis effects studied by numerical simulations: Cyclic loading-unloading of a realistic sand model.Geophysics, 71: 13-20.

Mukul, M. S., Tutuncu, A.N., 1994. Grain contact adhesion hysteresis: A mechanism for attenuation of seismic waves. Geophysical research letters, 21: 2323232.

Nejati, M., Paluszny, A., Zimmerman, R.W., 2013. Theoretical and numerical modeling of rocks hysteresis based on sliding of microcracks. American Rock Mechanics Association. Geomechanics Symposium: 13394.

Tucuncu, A. N., Podio, A.L., Sharma, M.M., 1998. Nonlinear viscoelastic behavior of sedimentary rocks, Part II: Hysteresis effects and influence of type of fluid on elastic moduli. Geophysics, 63: 195-203. 